\title{
NO BRASIL TOLERA-SE A ELEGIBILIDADE DE HOMOSSEXUAIS? ANÁLISE DO LAPOP-BRASIL EM RELAÇÃO A TOLERÂNCIA POLÍTICA ENTRE OS ANOS DE 2006 E 2019
}

Naiara Sandi de Almeida Alcantara ${ }^{1}$

\begin{abstract}
Resumo
Este texto é parte da tese de doutorado em desenvolvimento, e possui como objetivo discutir a intolerância política no Brasil em relação aos homossexuais. Escolheu-se trabalhar com esse grupo, pois se trata de uma minoria que desde a década de 90 passou a demandar publicamente e mais amplamente direitos sociais e políticos, e por isso deixou de ser um grupo obscurecido e tornou-se mais um alvo de intolerância. Para a realização da pesquisa utilizamos toda a série histórica do banco de dados do Latin American Public Opinion Project (LAPOP) aplicado no Brasil, para avaliar simultaneamente os efeitos da religiosidade. Portanto a metodologia utilizada foi a quantitativa, através da comparação de médias e teste de regressão. Partimos das seguintes hipóteses: i) a assiduidade, na prática religiosa, pode ser um preditor de maior objeção a participação do grupo minoritário pesquisado no âmbito político, ii) muito embora durante o período analisado (2006-2018) o Brasil tenha passado por uma série de mudanças legislativas em prol dos direitos dos homossexuais, ainda assim acredita-se que a população é majoritariamente intolerante a esse grupo, e iii) além das variáveis sobre religião existem condicionantes sociodemográficos que atualmente podem ser fortes preditores de intolerância aos homossexuais. Objetiva-se responder se a manifestação de atitudes de intolerância política em relação a homossexuais difere pela condicionante religiosidade. A partir das análises, verificou-se que de fato a frequência religiosa é uma variável preditora de intolerância, e que os mais religiosos tendem a ser mais intolerantes em todos os anos analisados, todavia, as médias de tolerância são altas e estão em movimento crescente. Assim como a legislação no país tem se tornando mais tolerante, os cidadãos também.
\end{abstract}

Palavras-Chave: Intolerância Política; Comportamento Político; Homossexualidade; América Latina.

\section{INTRODUÇÃO}

Muito se discute sobre intolerância política no Brasil, especialmente desde as últimas eleições presidenciais, que contaram com grande polarização social e política, mas a literatura sobre esse tema, que nos EUA está sendo discutido desde os anos 1950 por intermédio do estudo seminal de Stouffer, ainda é escasso em países da América Latina. Portanto, este artigo pretende discutir sobre a tolerância política nacional, já que o cenário brasileiro está apresentando crescimento de atos que representam

\footnotetext{
${ }^{1}$ Mestra em Ciências Sociais pela Universidade Estadual de Maringá (UEM). Doutoranda em Ciência Política pela Universidade Federal do Paraná (UFPR), e-mail: nayara_sandy@hotmail.com. ORCID: https://orcid.org/0000-00033343-5097
} 
explicitamente a acentuação da intolerância política, desde os protestos de 2013, e mais enfaticamente nas manifestações ocorridas entre 2015 e 2016 (RIBEIRO; FUNKS, 2019).

Segundo Gibson (2006), a intolerância política é um dos maiores problemas desde os processos de globalização e emigração, e a tolerância política é a única forma de amenizar os conflitos e confrontos, pois como demonstra o autor "tolerance is an essential endorphin of a democratic body politic (p.21)". Desde os primeiros estudos sobre tolerância, vários outros surgiram, então teorias foram sendo acumuladas, mas isso não significa que todas as questões acerca do tema foram sanadas, pois outras foram surgindo como, por exemplo, a forma de mensurar a intolerância. Apesar de haver uma série de estudos que propõem formas de medir a intolerância (como a de Sullivan, Piereson e Marcus), ao serem postas ao escrutínio acadêmico, sofreram críticas quanto ao mecanismo de mensuração.

Diante das questões que permanecem em aberto na literatura sobre tolerância, o objetivo principal do artigo será avaliar em que medida a religiosidade em sua dimensão individual (filiação denominacional e intensidade de participação) e nacional (grau de laicidade, abertura do mercado e contexto religioso) conformam o fenômeno da tolerância política no Brasil, em relação aos homossexuais. Pretende-se contribuir com a literatura nacional, através da análise de toda a série histórica do LAPOP $^{2}$ (Brasil), que resultou em uma investigação sobre a legislação vigente no que diz respeito aos direitos e garantias dos homossexuais, para verificar se o país é considerado tolerante ou não, e se esses dados influenciam em alguma medida a nível individual.

A metodologia utilizada foi a análise quantitativa e descritiva do LAPOP, em relação aos Survey aplicados bianualmente de 2006 a 2019. Utilizou-se como variável dependente a tolerância em relação aos homossexuais se candidatarem a cargos públicos, ou seja, um direito estendido a qualquer cidadão no Brasil. Já em relação às variáveis preditoras, foram escolhidas a frequência religiosa e a denominação religiosa, a legislação do país ${ }^{3}$, haja vista que o objetivo do artigo é analisar o nível individual e nacional no que tange a tolerância. Partiu-se das seguintes hipóteses: i) a assiduidade na prática religiosa pode ser um preditor de maior objeção a participação do grupo minoritário pesquisado no âmbito político, ii) durante o período analisado (2006-2019) o Brasil passou por uma série de mudanças legislativas em prol dos homossexuais, ainda assim acredita-se que a população é majoritariamente intolerantes a esse grupo, e iii) além das variáveis sobre religião

\footnotetext{
2 Survey Brasil -Latin American Public Opinion Project (LAPOP). Disponível em: https://www.vanderbilt.edu/lapop/brazil.php Último acesso em: 06 de abril de 2020

${ }_{3}^{3}$ Além de outras condicionantes demográficas.
} 
existem condicionantes sociodemográficas que atualmente podem ser fortes preditores de intolerância aos homossexuais.

O presente artigo é composto por quatro seções, além dessa introdução, a primeira trata de pesquisas precursoras na área de tolerância política e sobre a meneira como a tolerância está sendo definida, bem como, do desenvolvimento dessa área de pesquisa desde 1950 nos Estados Unidos e outros países desenvolvidos, na segunda seção tratamos sobre a tolerância política especificamente no Brasil e os condicionantes que estão sendo utilizados nas pesquisas nacionais, e a legislação nacional no que tange os direitos dos homossexuais. Em seguida apresentamos a seção metodologica, posteriormente os resultados compostos pelos testes das variáveis que consideramos significantes teoricamente, e por fim, as considerações finais.

\section{PESQUISAS PRECURSORAS}

A tolerância política já foi definida por uma série de autores, como Sullivan et al. (1982) que a definiu como um conceito relacionado a justiça processual, que são as regras postas para a manutenção do "jogo" em uma sociedade democrática. Então, ainda que contrários a determinados grupos, os indivíduos deverão estender a esses que menos gostam os direitos de: falar, publicar, concorrer a cargos públicos e demais direitos (SULLIVAN et al., 1982). Além disso, a intolerância é mais fácil cognitivamente que a tolerância, já que é mais fácil aprender estereótipos e preconceitos sobre os grupos diferentes, portanto, é necessário que os direitos civis sejam constantemente renovados, afinal, é comum o surgimento de novos grupos minoritários clamando por direitos e participação política (MARCUS et al.,1995).

As pesquisas sobre tolerância política tiveram início em 1950, através das pesquisas de Samuel Stouffer, que investigou a intolerância política em relação a certos grupos alvos, quais sejam: comunistas, socialistas e ateístas. Esses grupos foram escolhidos porque o cenário político já era desfavorável aos mesmos, que vinham sofrendo perseguições pelo então senador dos EUA, Joseph McCarthy, protagonista do movimento que ficou conhecido como macathismo (1950-1954), cuja proposta era a perseguição de todos que fossem considerados traidores do sistema, portanto quem se demonstrava contrário ao regime dominante capitalista e católico, eram considerados dissidentes e poderia sofrer sanções (STOUFFER, 1955).

Dentre os resultados encontrados por Stouffer, verificou-se que a maioria dos americanos eram intolerantes aos grupos minoritários pesquisados, concordando com a negação do direito dos 
integrantes desses grupos de falar em público, lecionar em escolas e trabalhar como balconista em lojas. Stouffer verificou que a intolerância estava relacionada a sensação de ameaça gerada nos entrevistados pelo grupo não conformista (STOUFFER, 1955; JACKMAN, 1972).

Além disso, a maioria dos entrevistados concordava que a cidadania daqueles admitidamente comunistas deveria ser subtraída; que livros escritos por eles não deveriam estar em bibliotecas públicas; que ao governo fosse permitido grampear e ouvir seus telefonemas privados, para que assim pudesse incriminar e prender indivíduos assumidamente pertencentes a esse grupo. Outros resultados da pesquisa indicam que os norte-americanos majoritariamente não concordavam com a livre concorrência no mercado de ideias, já que se opunham à oportunidade desses grupos classificados como não-conformistas exporem suas opiniões (STOUFFER, 1955; JACKMAN, 1972).

Para além da sensação de ameaça, Stouffer (1950) procurou também mapear condicionantes sociais das atitudes tolerantes, e verificou que dentre as variáveis testadas, a educação causava grande impacto sobre o comportamento tolerante, principalmente porque se mostrou relevante para a redução do sentimento de ameaça. A pesquisa indicou que quanto maior era o grau educacional do indivíduo, maior era sua capacidade cognitiva de compreender as normas democráticas em sua amplitude.

Após esse estudo inicial, os trabalhos de Prothro e Grigg (1960) e McClosky (1964) aparecem frequentemente como referências para o campo. O primeiro utiliza amostras das cidades de Arbor (Michigan) e Tallahassee (Florida) e verificou que, apesar da imensa maioria dos entrevistados manifestar aderência aos princípios gerais da democracia, quando o que está em questão é a aplicabilidade desses princípios (como liberdade de expressão e de organização) à grupos específicos (como os comunistas), tais princípios não são postos em prática. McClosky (1964) chega a resultados semelhantes, registrando que $94 \%$ da sua amostra aderia aos ideais da democracia, mas apenas $36 \%$ aceitava a aplicação desses ideais a grupos específicos. Para esse autor, os entrevistados falham em compreender que os princípios da democracia devem ser aplicados a circunstâncias concretas, e elegem alguns grupos como tão objetáveis que não são capazes de permitir a eles o exercício básico de direitos.

A pesquisa realizada por Stouffer na década de 1950 continuou sendo replicada nas décadas posteriores, e os resultados dessas pesquisas começaram a ser interpretados como positivos, por conta do declínio do sentimento de intolerância. Autores como Davis (1975) e Nunn et al. (1978) tentaram explicar esse aumento de tolerância através de mudanças no contexto social e político, como expansão da educação, revolução na comunicação, dentre outros fatores. Todavia, segundo Sullivan et al. (1982) essas explicações eram apenas especulações não confirmadas pelos dados. 
Sullivan et al. (1982) demonstraram que a sociedade norte-americana da época da pesquisa de Stouffer não realizava diferenciações significativas entre os comunistas, ateístas e socialistas, portanto em 1970, quando as questões sociais envolvendo os comunistas não eram mais relevantes para os canais noticiosos, a intolerância em relação aos 3 (três) grupos passou por um declínio. Todavia, essa constatação não demonstra que os americanos se tornaram mais comprometidos com os ideais abstratos da democracia já que ao longo das décadas vários outros grupos alvos de intolerância foram surgindo.

Diante desse cenário de pluralização dos alvos da intolerância política, esses autores propõe uma técnica alternativa de mensuração dessas atitudes, baseada na identificação inicial dos grupos principais de desafeição, os least-liked. Essa técnica consiste na apresentação prévia de uma lista contendo grupos ideologicamente diversos, indo da extrema direita à extrema esquerda, em que o entrevistado deve escolher o grupo que menos gosta. Na sequência os entrevistados são interrogados sobre o quanto aprovam ou desaprovam ações possíveis de serem praticadas pelo grupo escolhido (SULLIVAN et al., 1982).

Ainda que atualmente seja comum utilizar a técnica de least-liked, isto é - durante a aplicação do Survey identificar incialmente o grupo que o entrevistado menos gosta, para que dessa forma seja possível afirmar que o entrevistado não faz parte e nem é favorável aos grupos pesquisados, - os questionários do AmericanBarometer ${ }^{4}$ do Latin American Public Opinion Project (LAPOP) utilizados nesta pesquisa, não realizam a verificação do grupo menos gostado. Segundo Ribeiro e Borba (2020), a não utilização do método least-liked pode ocasionar erros de mensuração, porque pergunta indistintamente para qualquer entrevistado sobre o grupo alvo, portanto eventualmente homossexuais ou pessoas favoráveis a essa minoria também serão questionados. Mas faremos uso desses dados, porque já foram analisados e utilizados por Ribeiro e Borba (2020) e Ribeiro e Funks (2019), ademais os autores não o classificaram como "dado pobre", por auxiliar na produção de conhecimento sobre um tema ainda pouco discutido no Brasil.

\footnotetext{
${ }^{4} \mathrm{O}$ AmericasBarometer, uma das muitas e crescentes atividades do LAPOP, é a única pesquisa sobre opinião pública democrática e comportamento que abrange as Américas (Norte, Centro, Sul e Caribe). É um esforço do LAPOP para medir valores e comportamentos democráticos nas Américas usando amostras nacionais de probabilidade de adultos em idade de votar. Em 2004, a primeira rodada de pesquisas do AmericasBarometer foi implementada com onze países participantes; o segundo ocorreu em 2006 e incorporou 22 países em todo o hemisfério. Em 2008, 23 países das Américas foram incluídos e mais de 36.000 indivíduos. Em 2010, 26 países foram pesquisados, envolvendo mais de 43.000 entrevistas. Em 2012, 26 países foram incluídos novamente e mais de 41.000 pesquisas foram realizadas. A rodada de 2014 inclui pesquisas realizadas em 28 países das Américas e mais de 50.000 entrevistas. A rodada de 2016/17, que marca a última rodada do AmericasBarometer, foi realizada em 29 países e inclui mais de 43.000 entrevistas. O AmericasBarometer é o projeto de pesquisa regional mais abrangente do Hemisfério Ocidental (LAPOP, missiontradução livre).
} 


\section{TOLERÂNCIA POLÍTICA E A LEGISLAÇÃO BRASILEIRA}

Durante o levantamento da literatura, verificou-se que diferentemente do que acontece em democracias desenvolvidas, nas jovens democracias o número de trabalhos sobre tolerância é escasso. Por isso, nessa seção, revisamos o trabalho mais recente na área que utiliza como objeto de pesquisa o mesmo banco de dados que será utilizado nesse artigo.

Ribeiro e Borba (2020) realizaram uma pesquisa a nível nacional, utilizando como parâmetro de análise os períodos de 2015 e 2016 e os processos políticos compreendidos entre esses anos, como o impeachment da Presidente Dilma Rousseff. Para analisar o contexto nacional, os autores utilizaram um conjunto de variáveis do LAPOP, partindo da hipótese da relevância de recursos e atitudes, nos processos políticos que estavam ocorrendo na época supramencionada, isto é, partiram do pressuposto de que "[...] os mais escolarizados e mais comprometidos com a adesão normatiza à forma democrática sejam também os mais tolerantes" (RIBEIRO; BORBA, 2020).

Os autores realizaram uma série de testes, utilizando como variável depentende o quanto os entrevistados estavam dispostos a permitir que homossexuais se candidatassem a cargos públicos e algumas condicionates. Dentre os resultados verificou-se que a média de tolerância era maior que a metade e crescia nos últimos anos, também se utilizaram da integração das variáveis analisadas, a princípio separadamente, para criação do Índice de Tolerância Política (ITP) (RIBEIRO; BORBA, 2020).

Através do ITP, os autores inferiram que quanto mais o indivíduo adere aos conceitos abstratos da democracia, mais é tolerante. Sendo que o posicionamento ideológico, o Índice de apoio as instituições, a sensação de segurança e o sexo não apresentaram resultados significativos. Dentre as variáveis demográficas, a idade demonstrou ser inversamente significativa (quanto mais velho menor é a tolerância), e a escolaridade significante (quanto mais escolaridade mais tolerante). Os homossexuais foram analisados separadamente, e as variáveis que se mostraram significantes foram distintas da análise anterior, como por exemplo, sexo se mostrou significante, uma vez que as mulheres tendem a ser mais tolerantes. Escolaridade também apresentou significância, e a idade, novamente, mostrou-se inversamente significante. Dentre os demais condicionantes analisados nenhum apresentou significância (sensação de segurança, índice de democratismo, apoio as instituições e posicionamento ideológico) (RIBEIRO; BORBA, 2020). 
Os autores concluíram ser essencial analisar os níveis de tolerância dos brasileiros a luz de acontecimentos políticos relevantes. Os resultados das analises demonstraram que, de maneira geral, os índices que indicam tolerância são altos, mas estão passando por um declínio nos últimos anos. Apesar dos resultados não serem alarmantes refletem processos políticos como o impeachment da Presidente Dilma Rousseff. Além do mais, os dados encontrados foram semelhantes aos verificados nos EUA que, assim como o Brasil, elegeu candidatos populistas (RIBEIRO; BORBA, 2020).

Partimos do cenário de pesquisas já realizadas, pretendemos inovar no sentido do ano da pesquisa que utilizamos (2019) e a interação entre as variáveis do Survey e a análise da legislação brasileira em relação aos gays e lésbicas, por isso criamos o quadro 1, com uma síntese do panorama referente ao tratamento legislativo dispensado aos homossexuais.

\begin{tabular}{|c|c|c|c|c|c|}
\hline \multicolumn{2}{|c|}{ QUADRO 1- PANORAMA GERAL EM RELAÇÃO AOS DIREITOS DOS HOMOSSEXUAIS NO BRASIL } \\
\hline País & $\begin{array}{c}\text { Legalidade da } \\
\text { homossexualid } \\
\text { ade }\end{array}$ & $\begin{array}{c}\text { Relacionamento entre } \\
\text { pessoas do mesmo sexo }\end{array}$ & $\begin{array}{c}\text { Reconhecimento } \\
\text { do casamento, e } \\
\text { ano da legalização }\end{array}$ & $\begin{array}{c}\text { Adoção de } \\
\text { crianças e } \\
\text { ano da } \\
\text { legalização }\end{array}$ & $\begin{array}{c}\text { Leis anti- } \\
\text { discriminação, e } \\
\text { ano de criação. }\end{array}$ \\
\hline Brasil & $\begin{array}{c}\text { Sim, desde } \\
1980\end{array}$ & Legal & $\begin{array}{c}\text { Legal (União } \\
\text { Estável, 2011) }\end{array}$ & Legal, 2011 & Possui, 2019 \\
\hline
\end{tabular}

Fonte: Autora, a partir da legislação do país, 2020.

O quadro apresenta os principais direitos dos homossexuais no Brasil, muitas vezes fruto de lutas políticas travadas pelo movimento homossexual, que no país, surgiu a partir da década de 1970, formado por grupos institucionalizados ou não, composto por indivíduos com uma série de identidades sexuais. Segundo Facchini (2003), o movimento no Brasil pode ser dividido em três etapas que não são completamente delimitadas, mas servem para como um parâmetro para compreender como funcionou o movimento desde sua criação.

A primeira etapa concentrou-se no eixo Rio-São Paulo, e ficou conhecido por seu caráter mais libertário e alternativo. A fundação do primeiro grupo homossexual ocorreu em 1978, e foi denominado como SOMOS, que inicialmente era composto somente por homens. Depois de receber certa notoriedade, passou a receber novos membros. A partir desse grupo outros foram surgindo, representando o público lésbico. O encerramento desse período ocorre no final da década de 1980, coincidindo com o retorno da democracia, e a disseminação da AIDS-HIV, chamada pelo senso comum como "peste gay". Nesse segundo período, o movimento gay passou por um declínio (FACCHINI; 2003).

Já o terceiro período, que se inicia por volta da segunda metade da década de 1990, demonstra um crescimento do movimento, razão pela qual ficou conhecido como "reflorescimento", com maior 
participação da mídia e resposta do movimento a disseminação da AIDS-HIV, pautando-se nos direitos humanos, organização de eventos de rua para a visibilidade dos homossexuais, e a continuação do Encontro Brasileiro de Homossexuais (EBHO), que em seu início (1980) contou com a participação de 8 grupos e em 1995 já estava com 84 grupos (FACCHINI, 2003).

Todos os grupos criados durante os três períodos supramencionado, bem como os encontros realizados visavam a conquista de direito pelos homossexuais, ainda que os ganhos mais efetivos tenham se iniciado somente em 2011, em 1980 a homossexualidade já não era mais criminalizada, e ao menos teoricamente, os indivíduos não podiam mais ser presos sob a alegação de serem gays. Já as mudanças legislativas tiveram início por meio do do Projeto de Lei do Senado n. 612, de 2011,que alterou os artigos 1.723 e 1.726 do Código Civil, para permitir o reconhecimento legal da união estável entre pessoas do mesmo sexo. Reconheceu-se, portanto, como entidade familiar a união estável entre duas pessoas do mesmo sexo, que podem dessa forma, constituir família (Senado Federal, 2011).

Posteriormente passou a ser questionada a equidade da união estável em relação ao casamento. Tendo como parâmetro o artigo no 1790 do Código Civil - Lei 10406/02 ${ }^{5}$, em julgamento concluído em maio de 2017, decidiu-se pela inconstitucionalidade do referido artigo, pois continha disposição não isonômica para cônjuges e companheiros no que diz respeito à sucessão hereditária. Portanto, segundo o ministro Luíz Roberto Barroso, as novas partilhas, que estão em processo ainda podem ter um julgamento igual ao estabelecimento em casamento, assim o companheiro que está expresso na união estável terá os mesmos direitos do cônjuge do casamento civil, no que diz respeito as regras de sucessão (STF, 2011)

Para além das questões relacionadas a união de pessoas do mesmo sexo, o Brasil passou a contar com a criminalização da discriminação contra a comunidade de lésbicas, gays, bissexuais, transexuais e outros (LGBT+). Por decisão do Supremo Tribunal Federal (STF), a partir de junho de 2019 a homofobia e a transfobia passaram a ser consideradas crimes de racismo (Lei ${ }^{\circ}$ 7.716/1989), ante o reconhecimento da omissão legislativa, haja vista a não existência de tipo penal específico que incrimine referidas condutas no Código Penal brasileiro (STF, 2019).

\footnotetext{
${ }^{5}$ CC - Lei $n^{\circ} 10.406$ de 10 de Janeiro de 2002. Institui o Código Civil. Art. 1.790. A companheira ou o companheiro participará da sucessão do outro, quanto aos bens adquiridos onerosamente na vigência da união estável, nas condições seguintes: (Vide Recurso Extraordinário nº 646.721) (Vide Recurso Extraordinário no 878.694) I - se concorrer com filhos comuns, terá direito a uma quota equivalente à que por lei for atribuída ao filho; II - se concorrer com descendentes só do autor da herança, tocar-lhe-á a metade do que couber a cada um daqueles; III - se concorrer com outros parentes sucessíveis, terá direito a um terço da herança; IV - não havendo parentes sucessíveis, terá direito à totalidade da herança.Disponível em: https://www.jusbrasil.com.br/topicos/10608066/artigo-1790-da-lei-n-10406-de-10-de-janeirode-2002. Último acesso em: 06 de abril de 2020.
} 
Além disso, uma maneira de ampliar os direitos dos homossexuais é permitir que eles exerçam os mesmos direitos de casais heterossexuais, como por exemplo, a adoção de crianças. Isso é possível porque dentre os requisitos para a adoção, previstos no art. 197 do Estatuto da Criança e do Adolescente (ECA), é que sejam os adotantes casados ou possuam união estável, e ambos os institutos são estendidos a casais homoafetivos.

Diante do que fora exposto, acredita-se que o Brasil possui uma legislação bastante tolerante aos direitos sociais dos homossexuais, e também encoraja a tolerância em relação a esse grupo, por intermédio de leis e entendimentos jurisprudenciais que permitem que pessoas do mesmo sexo se casem e criminaliza a discriminação em relação aos mesmos. Nesse artigo parte de nossa metologia irá testar se essas mudanças legislativas pró-homossexuais influenciaram no sentimento de tolerância dos indivíduos. Outra parte se destinou a analisar outras condicionantes da variável a nível nacional que já estão sendo utilizadas nas pesquisas sobre o tema.

\section{METODOLOGIA}

A metodologia utilizada foi a quantitativa e descritiva, a nível nacional. Através de toda a série histórica de dados do LAPOP no Brasil (2006, 2008, 2010, 2012, 2016, 2018) realizamos uma análise levando em consideração a pesquisa de opinião e a legislação do país, e também um teste de regressão linear múltiplo para o ano de 2019 para avaliar a tolerância aos homossexuais tendo como principais intervenientes as variáveis individuais sobre religiosidade, e condicionantes sociodemográficas.

Partimos do pressuposto de que o Brasil possui uma legislação vigente bastante tolerante, porque os relacionamentos homossexuais não são criminalizados, além disso, a Suprema Corte reconheceu a união estável de casais do mesmo sexo, estendendo a estes os mesmos direitos dos casais heterossexuais. Ademais, desde a legalização da união homoafetiva, foi aberto o precedente de adoção de crianças por casais do mesmo sexo. O último direito adquirido por essa minoria no Brasil foi em relação a homofobia, que em 2019 passou a ser considerada crime de racismo.

As variáveis utilizadas foram: a) variável dependente: "D5. E agora, mudando de assunto e pensando nos homossexuais, o quanto o/a sr./sra. aprova ou desaprova que estas pessoas possam candidatar-se para cargos públicos?” Organizada em uma escala de 10 pontos, em que 1 significa descordo firmemente e 10 aprova firmemente (variável quantitativa); b) variáveis independentes: 
frequência religiosa ( Q5A), denominação religiosa $(\mathrm{Q} 3 \mathrm{CN})$; c) outras condicionantes: sexo, idade, escolaridade, adesão a democracia e ambiente de residência (urbano e rural).

Salienta-se que a justificativa teórica para utilização de cada uma das variáveis foram apresentadas nas seções anteriores, e em relação a última variável entende-se que a questão da localidade da residência é importante para a pesquisa, porque Stouffer (1950) constatou que grupos/indivíduos considerados de esquerda eram maiores alvos de intolerância dos entrevistados das cidades pequenas, para o contexto nacional a dualidade pode ocorrer entre o ambiente urbano e rural, pois Simmel (1967) demonstra que a vida metropolitana modifica a sociabilidade, a medida que as cidades são significante mais populosas que o campo, por isso o indivíduo citadino tem contato intenso, ainda que não intensional com indivíduos dotados de comportamentos e ideologias diferentes daqueles habituais. Enquanto o campestre tem mais facilidade para manter-de distinte de grupos distintos.

Tendo em vista as características das variáveis, acredita-se que o melhor teste a ser utilizado entre os anos é o teste de diferenças de médias (ANOVA), e se verificado a diferença, o teste de Tukey, em nível individual. Através do teste de tukey dividimos as médias da tolerância por frequência religiosa em dois grupos: 1) mais religiosos, compostos pelos indivíduos que frequentam mais de uma vez por semana, uma vez por semana e mais de uma vez por mês e 2) os menos ou nada religiosos, composto por quem frequenta raramente ou algumas vezes ao ano. Através dessa separação criamos um gráfico subpartido em dois para melhor a visualização e comparar os dois grupos entre os anos, bem como, analisar os resultados a luz da legislação do país.

Feito isso será possível realizar a análise longitudinal da tolerância dos religiosos aos homossexuais ao longo dos anos, responder a hipótese dois, e apontar a responta para a hipótese um, no caso de haver significância entre a variável dependente e independente, o teste de regressão servirá para medir a influência de uma variável na outra. Ademais, utilizaremos o teste de regressão linear múltipla para testar as demais variávais que nos interessam para responder a hipótese três, pois até o momento as variável sociodemográficas foram utilizadas para analisar a influência na tolerância política de maneira geral ou então focada nos homossexuais em rodadas anteriores do LAPOP, nossa proposta inova no sentido de rodar o modelo utilizando essa minoria em 2019.

\section{RESULTADOS}


A amostra bianual entre 2006 e 2018 somou 9.139 indivíduos entrevistados. Na primeira parte da aplicação da metodologia proposta, rodamos o teste da ANOVA, após constatado a significância entre as variáveis depentende e indepente, isto é, a existência de efeito do grupo sobre tolerar que homossexuais candidatem-se a cargos públicos, rodamos o teste de tukey que pode ser verificado através da tabela $1 .^{6}$

TABELA 1- SAÍDA DO TESTE DE TUKEY UTILIZANDO A VARIÁVEL DEPENTENDE E COMO FATOR A VARIÁL INDEPENTENDE PARA OS ANOS DE 2006, 2008, 2010, 2012, 2016 E 2018

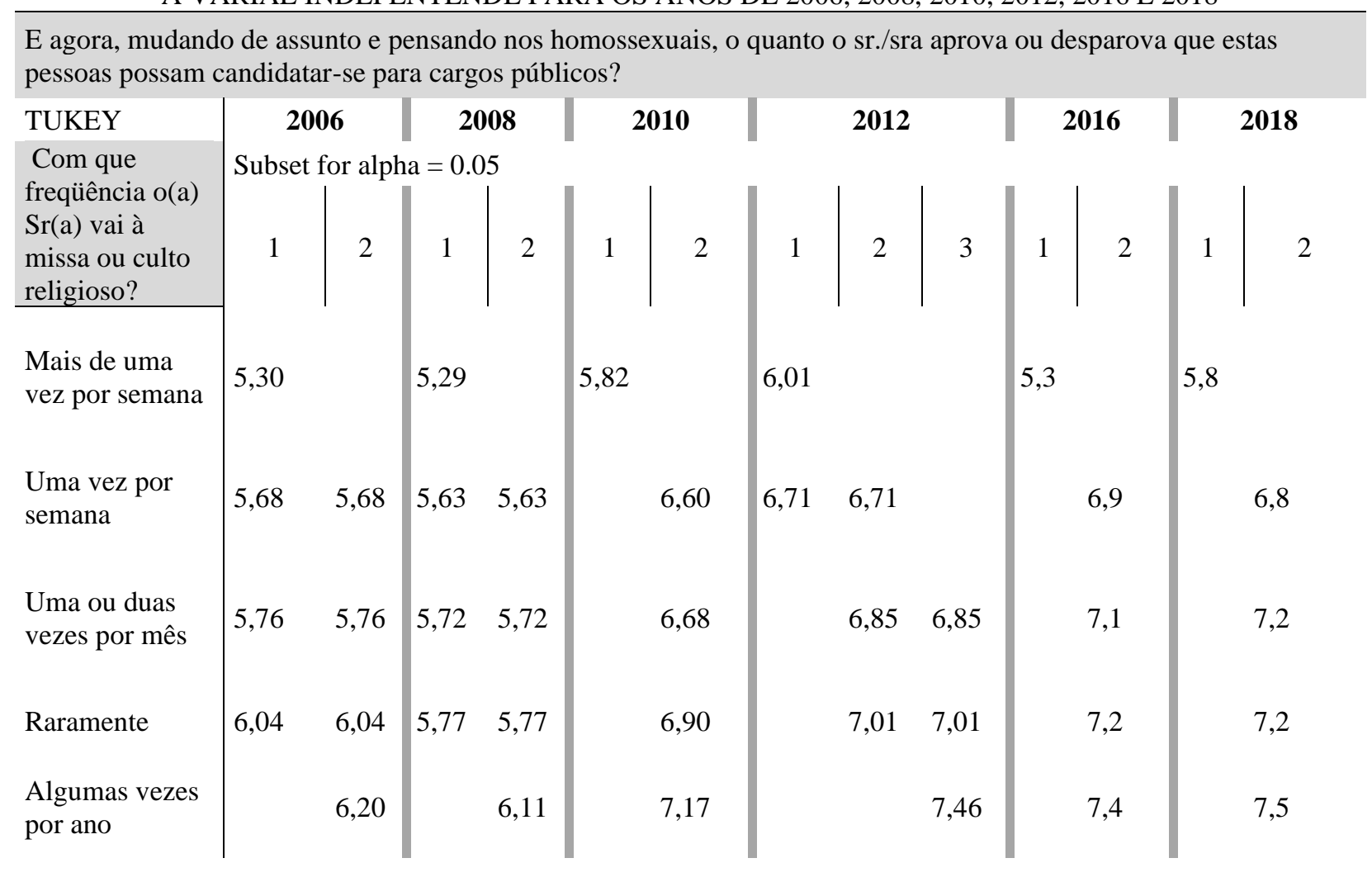

Fonte: Autora, a partir do LAPOP

A saída do Tukey somente apresenta os resultados divididos em grupos quando há diferenças de médias. Através da tabela do Tukey para 2006, constatamos a existência de diferenças entre os grupos mais religiosos (que vão a missa, cultos e afins) mais de uma vez por semana (5,30 média), para o grupo que vai algumas vezes por ano $(6,20)$.

Como o índice de tolerância é medido em uma escala de 10 pontos, e mesmo para os mais religioso a média é superior a 5, entende-se que de maneira geral a população é tolerante a

\footnotetext{
${ }^{6}$ Organizamos os dados bianualmente, porque essa era a proposta de aplicação do LAPOP no Brasil, contudo alguns Surveys foram aplicados em anos anteriores e lançados no ano seguinte, como o de 2018 que foi lançado em 2019.
} 
homossexuais se candidatarem a cargos públicos, todavia, quanto menos religioso maior é a tolerância, e como pode ser verificado nos anos seguintes essa diferença tende a aumentar significativamente. Através da tabela do Tukey para 2008, percebeu-se que há diferenças entre os grupos mais religiosos (que vão a missa, cultos e afins) mais de uma vez por semana (5,29 média), para o grupo que vai algumas vezes por ano $(6,11)$.

Resultado semelhante ao de 2008 e 2006 foi encontrado em 2010, através da tabela tem-se que há diferenças entre os grupos mais religiosos (que vão a missa, culto e afins) mais de uma vez por semana (5,82 média), para os grupos: que vão uma vez por semana $(6,6)$, uma ou duas vezes por mês $(6,68)$, raramente $(6,9)$, algumas vezes por ano $(7,17)$.

Em 2012, é possível afirmar que há diferenças entre três grupos, àqueles que frequentam mais de uma vez por semana $(6,01)$ se diferenciam dos que vão uma vez por semana $(6,71)$, uma ou duas vezes por mês $(6,85)$, raramente $(7,01)$, que por sua vez se diferenciam do grupo que vai apenas algumas vezes por ano $(7,46)$.

Já 2016 apresentou diferenças entre os grupos mais religiosos que participam mais de uma vez por semana $(5,3)$ em relação aos grupos que participam uma vez por semana $(6,9)$, uma ou duas vezes por mês $(7,1)$, raramente $(7,2)$ e algumas vezes por ano $(7,4)$. Igualmente para o ano de 2018 , em que verificamos diferenças médias entre os grupos mais religiosos que frequentam mais de uma vez por semana $(5,8)$, para os grupos que participam uma vez por semana $(6,8)$, uma ou duas vezes por mês $(7,2)$, raramente $(7,2)$ e algumas vezes por ano $(7,5)$.

Para compreender melhor a tabela um, rodamos dois gráficos para os resultados apresentados na tabela, a fim de dividir os entrevistados em mais religiosos e menos religiosos, e interpretar esses resultados a luz da legislação em relação aos homossexuais. 

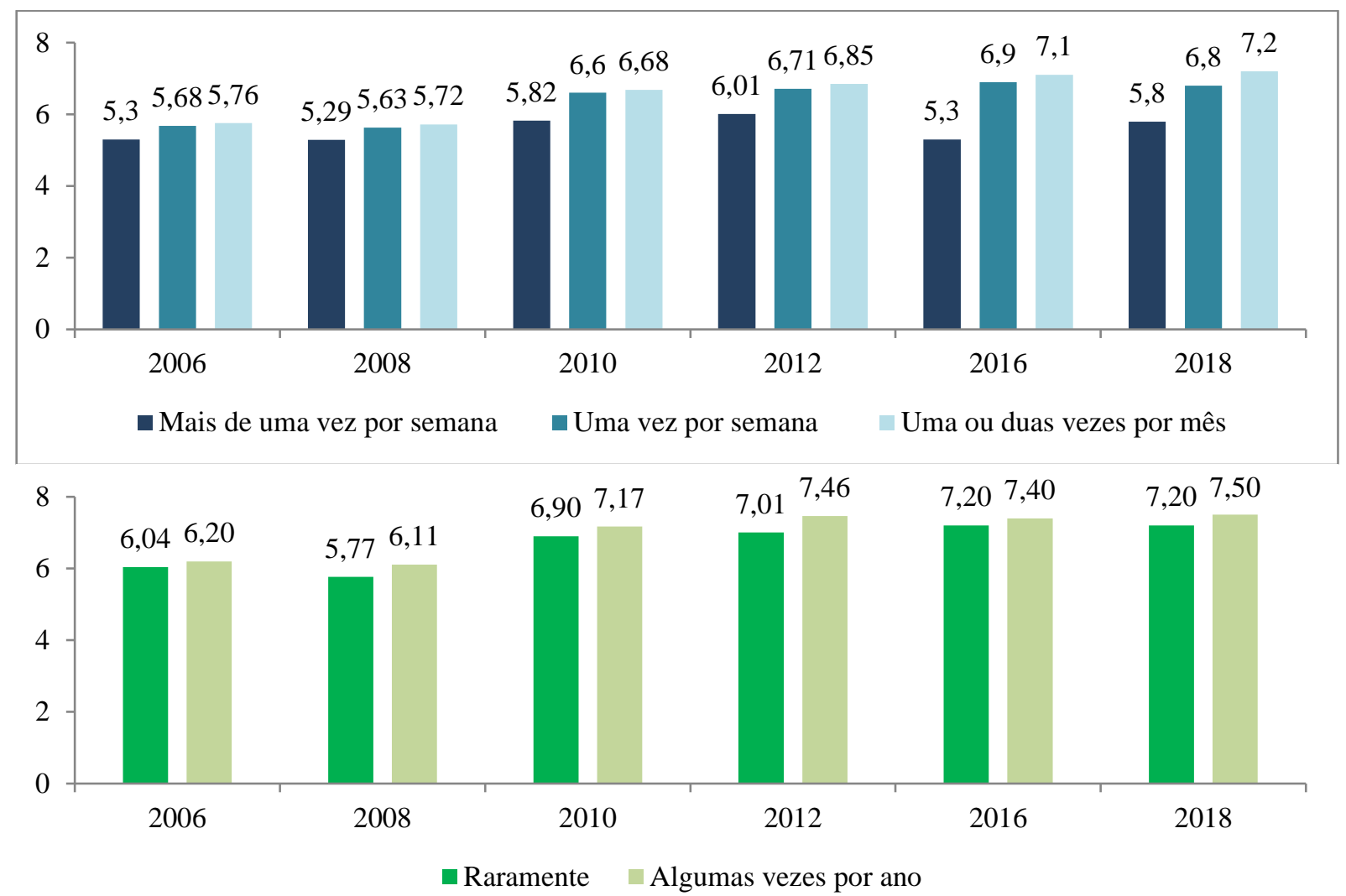

Fonte: Autora, a partir do LAPOP

Conforme o gráfico 2 subpartido em duas projeções gráficas podemos verificar que existem dois dados que estão em movimento crescente: o de religiosos tolerantes e o de não religiosos também tolerantes, apesar do grupo religioso ter alguns decréscimos entre os anos, em 2018 volta a crescer. Mesmo entre os mais religiosos os grupos se subdividem em três, e os indivíduos mais tolerante são os que participam apenas uma vez ao mês, isto é, quanto menor a participação religiosa maior é a tolerância.

Ainda assim, infere-se que com o passar dos anos está ocorrendo um aumento da tolerância tanto entre religiosos, quanto entre os não religiosos. Em contrapartida, em um movimento óbvio, os intolerantes estão diminuindo. Os dados encontrados respondem a nossa questão sobre a legislação, quando analisamos a tolerância a luz das mudanças políticas no país, pois os ganhos legislativos para os homossexuais se iniciaram mais proeminentemente no Brasil em 2011, através da regulamentação da união homoafetiva e possibilidade de adoção de crianças por casais do mesmo sexo, e posteriormente o entendimento jurisprudencial de 2017 que equiparou em todos os sentidos o casamento de homossexuais a dos heterossexuais. Portanto, podemos infererir que conforme o país torna-se mais tolerante, os indívuos também, comexceção dos religiosos. 
Apesar dos resultados apresentados percebem-se algumas nuances entre as barras, primeiro que em todos os anos, invariavelmente, os religiosos são menos tolerantes que os não religiosos. As médias para os dois gráficos aumentam, mas os não religiosos chegam mais próximo de 8 pontos, o que representa alta tolerância. Para os mais religiosos nota-se um movimento de declínio das barras entre 2012 e 2016, em 2018 as médias voltam a aumentar.

Após, constatarmos a existência de correlação entre a variável dependente e a principal variável indepentende, sobre a frequência religiosa. Foi necessário utilizar o teste de regressão linear múltiplo para entender o quanto a frequência religiosa interfere negativamente no ato de tolerar, ademais testamos a outra variável indepentende sobre religião, denominação religiosa. Além disso, acrescentamos ao modelo as variáveis demográficas apontadas pela litatura como importantes para a discussão de tolerância política.

\section{TABELA 2 -TESTE DE REGRESSÃO LINEAR MULTIPLA}

\begin{tabular}{lccccc} 
Modelo 1 & $\begin{array}{c}\text { Coeficientes não } \\
\text { padronizados }\end{array}$ & $\begin{array}{c}\text { Coeficiente } \\
\text { padronizado }\end{array}$ & \\
& B & Erro padrão & Beta & \multicolumn{1}{c}{ T } & Sig. \\
(Constant) & 3,098 &, 623 & & 4,971 &, 000 \\
Ativismo religioso $^{7}$ &, 384 &, 060 &, 166 & 6,452 &, 000 \\
Idade $^{8}$ &,- 010 &, 006 &,- 051 & $-1,823$ &, 068 \\
Escolaridade $^{9}$ &, 163 &, 024 &, 192 & 6,756 &, 000 \\
Sexo $^{10}$ &, 658 &, 167 &, 101 & 3,944 &, 000 \\
Confiança democratica $^{11}$ &, 190 &, 047 &, 104 & 4,039 &, 000 \\
Denominação religosa $^{12}$ &, 001 &, 000 &, 072 & 2,837 &, 005 \\
Urbano e rural $^{12}$ &,- 257 &, 247 &,- 027 & $-1,041$ &, 298
\end{tabular}

Fonte: Autora, a partir do LAPOP

Dependent Variable: d5 (Tolerância a homossexuais candidatarem-se a cargos públicos

$\mathrm{B}$ - valor que representa o ponto em que a reta cruza o eixo y

$\mathrm{t}$ - coeficiente divido pelo erro padrão

\footnotetext{
${ }^{7}$ Q5A. Com que freqüência o(a) sr./sra. vai à missa ou culto religioso? (1) Mais de uma vez por semana/(2) Uma vez por semana/(3) Uma vez por mês/(4) Uma ou duas vezes por ano/ (5) Nunca ou quase nunca.

${ }^{8} \mathrm{Q} 1$. Idade superior a 16 anos, em ordem crescente.

${ }^{9}$ Ed. Educação medida em anos de estudo, em ordem crescente.

${ }^{10}$ Q2. Sexo: 1-Masculino e 2-Feminino

${ }^{11}$ ING4. Mudando de assunto de novo, a democracia tem alguns problemas, mas é melhor do que qualquer outra forma de governo. Até que ponto concorda ou discorda desta frase? Medida em escala de 1 para descorda muito a 7 concorda muito.

${ }^{12}$ Q3CN. Qual a sua religião, se tiver? (01) Católico (02) Protestante [...] (03) Outra religião oriental

(05) Evangélica pentecostal (07) Religiões Tradicionais ou nativas (04) Nenhuma (11) Agnóstico ou ateu.
} 
Analisando a tabela 2 verificamos que os indivíduos menos frequentantes religiosamente, tendem a tolerar em mais $16,6 \%$ os homossexuais se candidatem a cargos públicos, e ser ateu aumenta em 7,2\% a tolerância. Em relação as variáveis demográficas, sexo e educação deram significativa, isto é ser mulher aumenta em 10,1\% a probabilidade de ser tolerante a homossexuais, e os mais educados formalmente também tendem a ser 19,2\% mais tolerantes. Já a idade não apresentou significância nesse modelo, mas o valor de p não foi tão mais alto do que o aceitável $(0,68)$, ademais mantemos essa variável no modelo porque ela é importante segundo a literatura, e se admitissemos sua significância a cada ano de idade que aumenta, menos $5,1 \%$ o indivíduos tendem a tolerar homossexuais, isto é, os mais velhos tendem a ser mais intolerantes.

Inserimos duas variáveis no modelo que são indicadas pela literatura como significantes no ato de tolerar de maneira geral, a confiança na democracia e o local onde o indivíduo reside. Somente confiança na democracia apresentou significância, confiar no modelo democrático aumenta em 10,4\% as chances de tolerar. Já o ambiente, urbano e rural, não apresentou significância, todavia ao rodarmos um modelo sem essa variável verificamos que a capacidade de predição do meu modelo de maneira geral diminuiu, então para aumentar a robustez do teste decidimos manter a variável.

Para rodar o teste de regressão também pedimos alguns outros testes para idenficar se os prérequisitos para o tipo de teste (linear multiplo) estavam sendo cumpridos. Como a ausência de multicolinearidade, isto é, a não existência alta $(0,7 / 0,8)$ de correlação entre as variáveis independentes, e os resíduos estão normalmente distruídos no gráfico de dispersão. A análise resultou em um modelo estatisticamente significativo ( $\mathrm{p}<0,05)$, no entando o modelo que foi utilizado teve capacidade de $10,9 \%$ de previsão da variável dependente, conforme pode ser verificado nas tabelas em anexo ${ }^{13}$.

\section{CONSIDERAÇÕES FINAIS}

Países da América Latina, como o Brasil, estão passando por uma série de mudanças políticas e acentuada disseminação pública de ideais conservadores, mesmo diante disso ainda são poucos os trabalhos que discutem sobre o tema, especialmente tratando a respeito de grupos minoritários. $\mathrm{O}$ LAPOP foi um dos primeiros Surveys a inserir em sua pesquisa uma bateria de questões que podem

\footnotetext{
${ }^{13}$ Não disponibilizamos o banco online, porque os bancos utilizados estão disponíveis no site do LAPOP, através do projeto Americas Barometer, acesso em: < http://datasets.americasbarometer.org/database/index.php?freeUser=true>, último acesso em 27 de jun de 2020. Ademais não foram disponibilizados scrips, porque as análises foram realizadas no spss, conforme os procedimentos descritos na sessão metodologica.
} 
ser utilizadas para medir tolerância, portanto é a partir dos bancos dessa organização que se iniciou a produção de artigos aqui no Brasil, conforme apresentamos na análise da literatura. Os resultados encontrados por esse artigo corroboram parte dos resultados apresentados pela literatura corrente, mas não se verificou diminuição ou alteração do sentido da tolerância em decorrência de mudanças mais evidentes na legislação em relação aos homossexuais.

Desde o primeiro ano de análise (2006) já se verifica que as médias de tolerância em relação a homossexuais se candidatarem a cargos públicos é superior a 5, por isso infere-se que os indivíduos já eram mais tolerantes que intolerantes. Mas como existe diferença de média, e as médias maiores se encontram no segundo grupo, entende-se que quanto mais religioso menos tolerante. Observa-se que as médias em geral estão crescendo, mesmo entre os religiosos, mas é inegável que os menos religiosos são mais tolerantes e se aproximam de 8 pontos de média.

Já em relação a análise do banco dividido em 2 grupos em comparação com a legislação, relacionando com a variável sobre tolerância aos homossexuais, percebeu-se que os não religiosos são sempre mais tolerantes que os frequentantes mais assíduos, todavia em ambos os grupos (mais e menos religiosos) existe uma parcela de intolerância. Essa parcela está diminuindo com o passar dos anos, conforme a legislação do país torna-se mais tolerante a essa minoria, a população também apresenta crescimento de tolerância.

Concluímos que a hipótese I foi confirmada, porque de fato a assiduidade na prática religiosa demonstrou ser um preditor de maior intolerância, tanto pelo teste da ANOVA, quanto pela regressão. Já a hipótese II foi refutada, pois conforme ocorrem as mudanças legislativas os cidadãos estão se tornando mais tolerantes, mas sempre os mais religiosos são menos tolerantes, afinal, os ateus e menos frequentes apresentam resultado positivo em tolerar. Por fim, a hipótese III foi confirmada, no sentido de que as variáveis testadas pela literatura como fortes condicionantes de tolerância geral, ou aplicadas aos homossexuais em anos anteriores, ainda tem forte capacidade de predição, como sexo, educação, confiança na democracia.

Entende-se que o objetivo do artigo foi particialmente cumprido, porque conseguimos responder as hipóteses propostas, mas ainda não apresentamos um teste que medisse o nível nacional em uma análise estatística, como se pretende realizar na tese, mas apresentamos dados atuais sobre tolerância aos homossexuais com um modelo robusto de regressão e constamos que mesmo diante das atuais mudanças políticas existe uma tendência de crescimento da tolerância ao grupo analisado, mesmo entre os religiosos. 


\section{REFERÊNCIAS}

DAVIS, James A., Communism, Conformity, Cohorts, and Categories: American Tolerance in 1954 and 1972-73. American Journal of Sociology, Vol. 81, No. 3 (Nov., 1975), pp. 491-513

FACCHINI, Regina. Movimentohomossexual no Brasil:recompondo um histórico. Cad. AEL, v.10, n.18/19, 2003, p.81-122.

GIBSON, J. L. Enigmas of Intolerance: Fifty Years after Stouffer's Communism, Conformity, and Civil Liberties. Perspectives on Politics. Vol. 4, N.1, 2006.

JACKMAN, R. W. Political Elites, Mass Publics, and Support for Democratic Principles. The Journal of Politics, Vol. 34, N.3, 1972, p. 753-773.

MARCUS, G.E.; SULLIVAN, J.L.; THEISS-MORSE, E. WOOD, S.L., With Malice Toward Some. Cambridge: Cambridge University Press, 1995.

MCCLOSKY, Herbert. Consensus and Ideology in American Politics. The American Political Science Review, Vol. 58, No. 2, 1964, p. 361-382.

NUNN, C.; CROCKETT, H.; ALLEN, W.J. Tolerance and Nonconformity. San Francisco: JosseyBass, 1978.

PROTHRO, James W.; GRIGG, Charles M. Fundamental Principles of Democracy: Bases of Agreement and Disagreement. The Journal of Politics, V. 22, ed. 2, 1960, p. 276-294

RIBEIRO, Ednaldo; BORBA, Julian. Tolerância Política no Brasil Recente: evolução de indicadores e condicionantes. Cad. CRH, vol.32 no.87 Salvador, 2020. p. 641-657. https://doi.org/10.9771/ccrh.v32i87.23749

Senado Federal, Atividade Legislativa, Autoria: Senadora Marta Suplicy (PT/SP). Disponível em: https://www25.senado.leg.br/web/atividade/materias/-/materia/102589. Último acesso em: 06 de abril de 2020

SIMMEL, Georg. A metrópole e a vida mental, 1902 trad. Sérgio Marques dos Reis. in: VELHO, Otávio Guilherme (org.) O fenômeno Urbano, Rio de Janeiro: Zahar, 1967.

SUlliVAN, J. L., PIERESON, J., MARCUS G. E. Political Tolerance and American Democracy. Londor: University of Chicago Press, 1982.

Supremo Tribunal Federal (STF). STF enquadra homofobia e transfobia como crimes de racismo ao reconhecer omissão $2019 . \quad$ legislativa. Disponível em: https://portal.stf.jus.br/noticias/verNoticiaDetalhe.asp?idConteudo=414010. Último acesso em: 06 de abril de 2020

Supremo Tribunal Federal (STF). Supremo reconhece união homoafetiva. 2011. Disponível em: http://www.stf.jus.br/portal/cms/verNoticiaDetalhe.asp?idConteudo=178931. Último acesso em: 06 de abril de 2020 
STOUFFER, Samuel A. Communism, Conformity and Liberties: A Cross- Section of the Nation Speaks Its Mind. Nova York: Doubleday, 1955

ANEXOS:

TABELA 1- ESTATÍTICA DESCRITIVA DAS VARIÁVEIS UTILIZADAS NA

ANÁLISE

\begin{tabular}{l|r|r|r}
\hline $\begin{array}{c}\text { Variávei } \\
\mathrm{s}\end{array}$ & \multicolumn{1}{|c|}{ Mean } & Std. Deviation & \multicolumn{1}{c}{$\mathrm{N}$} \\
\hline $\mathrm{d} 5$ & \multicolumn{1}{c}{6,8855} & 3,24046 & 1389 \\
\hline $\mathrm{q} 5 \mathrm{a}$ & 2,7919 & 1,40216 & 1389 \\
\hline $\mathrm{q} 2$ & 38,9345 & 16,00655 & 1389 \\
\hline $\mathrm{ed}$ & 8,9820 & 3,83246 & 1389 \\
\hline $\mathrm{q} 1$ & 1,4975 &, 50017 & 1389 \\
\hline ing4 & 4,8431 & 1,77839 & 1389 \\
\hline $\mathrm{q} 3 \mathrm{cn}$ & 39,8337 & 228,31459 & 1389 \\
\hline ur & 1,1346 &, 34145 & 1389
\end{tabular}

FONTE: AUTORA, LAPOP

TABELA 2- MODEL SUMMARYB (SUMÁRIO DO MODELO) DA REGRESSÃO

\begin{tabular}{|c|c|c|c|c|c|c|c|c|c|c|}
\hline \multirow[t]{2}{*}{ Model } & \multirow[b]{2}{*}{$\mathrm{R}$} & \multirow[b]{2}{*}{$\begin{array}{c}\mathrm{R} \\
\text { Square }\end{array}$} & \multirow[b]{2}{*}{$\begin{array}{c}\text { Adjusted } \\
\text { R } \\
\text { Square }\end{array}$} & \multirow[b]{2}{*}{$\begin{array}{l}\text { Std. Error } \\
\text { of the } \\
\text { Estimate }\end{array}$} & \multicolumn{5}{|c|}{ Change Statistics } & \multirow{3}{*}{$\begin{array}{l}\text { Durbin- } \\
\text { Watson } \\
\end{array}$} \\
\hline & & & & & \begin{tabular}{|c|}
$\mathrm{R}$ \\
Square \\
Change
\end{tabular} & F Change & df1 & df2 & \begin{tabular}{|c|} 
Sig. F \\
Change
\end{tabular} & \\
\hline 1 & ,331 & , 109 & , 105 & 3,06583 & , 109 & 24,232 & 7 & 1381 & 000 & \\
\hline
\end{tabular}

FONTE: AUTORA, LAPOP 